\title{
Spatial patterns and associated factors' of Early Marriage among Reproductive age women in Ethiopia: a Secondary Analysis of EDHS 2016
}

Zemenu Tessema Tadesse ( $\sim$ zemenut1979@gmail.com ) University of Gondar

Research article

Keywords: Early marriage, childhood marriage, Ethiopia

Posted Date: December 4th, 2019

DOI: https://doi.org/10.21203/rs.2.18181/v1

License: (c) (i) This work is licensed under a Creative Commons Attribution 4.0 International License.

Read Full License 


\section{Abstract}

Background: Besides, the presence of national law, the country has to set up its own mid-term and long term goals to bring about a significant reduction in child marriages in Ethiopia. To achieve this, determining the spatial pattern of early marriage and factors associated is important for government, other concerned bodies, program implementers and policy developers to end up early childhood marriage. Thus, the aim of this study was to assess the spatial patterns and associated factors of Early marriage among reproductive-age women in Ethiopia.

Methods: This study analyzed retrospectively a cross-sectional data on a weighted sample of 11,646 women aged 15-49 years after requesting from Ethiopian Demographic and Health Survey 2016 via the link www.measuredhs.com. ArcGIS version 10.7 software was used to visualize spatial distribution for Early marriage. The Bernoulli model was applied using Kilduff SaTScan version 9.6 software to identify significant purely spatial clusters for Early marriage in Ethiopia multiple logistic regression analysis was used to identify factors associated with early marriage. Finally, variables with a $p$-value $<0.05$ were considered as statistically significant.

Results: In this analysis, about $62.8 \%$ (95\%Cl: $61.9,63.74 \%)$ of the study participants were married before they reached 18 years. The overall median age at first marriage was 17.1 with IQR 5 years. The high clustering of early marriage was located in Amhara, Afar, and Gambella Regions. In spatial Scan statistics 87 clusters $(R R=1.28$, P-value $<0.001)$ significant primary clusters were identified. The associated factors of early marriage were lesser among women's attending primary $(A O R=0.60 ; 95 \% \mathrm{Cl}$ : $0.51,0.71)$, secondary $(A O R=0.19 ; 95 \% \mathrm{Cl}: 0.13,0.26)$ and tertiary education $(A O R=0.11 ; 95 \% \mathrm{Cl}: 0.07$, 0.18). Similarly, women found in Addis Ababa were at a lesser risk of early marriage compared to other regions of the country.

Conclusion: Marriage below age 18 was high in Ethiopia. High-risk area of early marriage was located in Amhara, Afar, and Gambella and special attention should be given for identified risk areas. Therefore, providing educational opportunities to young girls was important in addition to inhibiting the marriage of girls under 18 years.

\section{Background}

Early marriage is defined as the marriage of a girl $<18$ years of age and is a common phenomenon worldwide(1). According to the United Nations Children's Fund (UNICEF), Each year, 12 million girls are married before the age of 18 years (2). The problem is highly prevalent in Asia (45\%) followed by subSaharan Africa (39\%), Latin America (23\%) and 18\% in the Middle East and North Africa(3). As an illustration, in Africa, the prevalence of early marriage was $31.4 \%$ in Zambia(4). Similarly, in Ethiopia, the percentage of women marrying before age 18 has declined slightly since 2011 from 63\% to 58\%. During the same period, the median age at first marriage among women age 25-49 has increased from 16.5 years to 17.1 years(5). 
Childbearing below the age of 18 years is associated with a higher rate of mortality, eclampsia, postpartum hemorrhage, HIV infection, malaria, and obstructed labor $(6,7)$. In addition, early marriage is associated with lower levels of schooling for girls, higher intimate partner violence and poor maternal and child nutrition status (6). The probability of being stunted and wasting is higher among children born from early married women. The consequence of early marriage is not limited to the mother and her child, it has also social, economic, and political implications(8).

Despite the presence of national laws in Ethiopia, a marriage of girls $<18$ years of age is common and it affects a number of girls(9). The problem may worsen when it exists with a high prevalence of HIV and other sexually transmitted diseases, malnutrition, cervical cancer, and others. The governments of Ethiopia have adopted strategies to end the practice and investments are being made to that effect, including by promoting girls' education and sexual and reproductive health and rights. But ending child marriage requires a multifaceted approach focused on the girls, their families, the community, and the government.

In Ethiopia, several studies identified that education, harmful tradition practice, income, family size, media exposure and culture of the community were the significant factors associated with early marriage(916). So far different studies in Ethiopia done to identify the factors associated with early marriage. The spatial pattern of early was not done before. Identifying the spatial pattern of early marriage in Ethiopia can help health planners and policymakers for intervention to decrease early marriage

Therefore, besides, the presence of national law, the country has to set up its own mid-term and long term goals to bring about a significant reduction in child marriages in Ethiopia. To achieve this, showing the spatial pattern and its factors associated are important for government, other concerned bodies, program implementers and policy developers to end early childhood marriage. Thus, the aim of this study was to assess the spatial patterns and associated factors of Early marriage among reproductive-age women in Ethiopia.

\section{Methods}

\section{Study area, data source, sample}

The study was based on the Ethiopian demographic and health survey (EDHS) 2016 data set. Ethiopia is situated in the Horn of Africa and has 9 Regional states (Afar, Amhara, Benishangul-Gumuz, Gambela, Harari, Oromia, Somali, Southern Nations, Nationalities, and People's Region (SNNP) and Tigray) and two Administrative Cities (Addis Ababa and Dire Dawa).

Approval letter for the use of this data was gained from the Measure DHS and the data set was downloaded from the Measure DHS website; www.meauredhs.com. The survey covered all the nine regions and the two city administrations of Ethiopia and participants were selected through a stratified two-stage cluster sampling technique. The full details of the methods and procedures used for the collection of the EDHS data have been published elsewhere(5). The survey collected information from a 
nationally representative sample of 16,683 women aged 15-49 years. finally, 11,646 eligible women were included in this study which was nested within 643 clusters across the country.

\section{Source and study population}

The source population was all reproductive-age women within five years before the survey in Ethiopia and all women whose age between 15-49 years in the enumeration areas within five years before the survey was the study population. A total of 18008 households were selected and 16,650 were successfully interviewed. A total of 11646 women who had married five years preceding the survey were included in this analysis (Figure 1).

\section{Variables of the study}

The outcome variable for this study was age at first marriage (binary) either below 18 or 18 and above (if a woman married before age 18 is considered as early marriage and if women married at the age of 18 and above considered as not early marriage ). The variables that may influence early marriage include age, religion, respondents' highest education attainment, educational status of husbands/parents, occupational status of respondents, occupational status of parents, media exposure, and household wealth status, residence, and region(9-16).

\section{Data collection procedure, tools, and quality control}

The data was obtained from Individual Records (IR) file EDHS 2016 survey year at www.dhsprogram.com website. The web provided the data only for authorized users. Data also contained longitude and latitude coordinates. Ethiopian Demographic and Health Survey data were collected by two-stage stratified sampling. Each region of the country was stratified into urban and rural areas. The EDHS 2016 was used as a structured and pre-tested questionnaire for data collection The 2016 EDHS data collectors used tablet computers to record responses during the interview. The tablet was equipped with Bluetooth technology to enable remote electronic transfer of files for this study the detail is found at (5).

\section{Spatial autocorrelation and hot spot analysis:}

We used Arc GIS 10.7 software for spatial autocorrelation and detection of hot spot areas analysis. Spatial autocorrelation (Global Moran's I) statistic measure was used to assess whether an early marriage was dispersed, clustered, or randomly distributed in Ethiopia. Moran's I values close to -1 indicates early marriage dispersed, close to +1 indicates clustered, and if Moran's I value zero indicates randomly distributed (17). Hot Spot Analysis (Getis-Ord Gi* statistic) of the z-scores and significant pvalues tells the features with either hot spot or cold spot values for the clusters spatially.

\section{Spatial interpolation:}


The spatial interpolation technique is used to predict early marriage for unsampled areas based on sampled EAs. For the prediction of unsampled EAs, we used deterministic and geostatistical Ordinary Kriging spatial interpolation technique using ArcGIS 10.7 software.

\section{Spatial scan statistics:}

We employed Bernoulli based model spatial scan statistics to determine the geographical locations of statistically significant clusters for early marriage using Kuldorff's SaTScan version 9.6 software (18). The scanning window that moves across the study area in which early marriage was taken as cases and those women who married after age 18 and above as controls to fit the Bernoulli model. The default maximum spatial cluster size of $<50 \%$ of the population was used as an upper limit, allowing both small and large clusters to be detected, and ignored clusters that contained more than the maximum limit with the circular shape of the window. Most likely clusters were identified using p-values and likelihood ratio tests on the basis of the 999 Monte Carlo replications.

\section{Statistical analysis}

STATA version 14 was used for data analysis. Then data cleaning was carried out. Both descriptive and analytical studies were done. Both bi-variable and multiple logistic regression analysis was performed to determine the existing association. Initially, bivariate analysis was performed and variables with a p-value of 0.2 and below were used for further analysis in the multivariable logistic regression model. At the same time, Crude Odds Ratio (COR) and Adjusted Odds Ratio (AOR) with their corresponding confidence interval $(\mathrm{Cl})$ also determined for the bivariate and multivariate logistic analysis, respectively. Finally, a pvalue of less than 0.05 level of significance was used to declare the significance of association in the multi-variable model.

\section{Results}

In this analysis, about $62.8 \%$ (95\%CI: $61.9,63.74 \%)$ of the study participants were married before they reached 18 years. The overall median age at first marriage was 17.1 years with IQR 5. The majority, 88.95\%), of the respondents were rural areas. More than half (60.61\%) of respondents had no formal education. Near to three-fourth, $(77.9 \%)$, of the respondents had no exposure to mass media. (Table1).

\section{Spatial distribution of Early Marriage in Ethiopia.}

\section{Spatial Autocorrelation}

The spatial distribution of Early marriage in Ethiopia was non-random in the EDHS 2016 dataset. The global Moran's I value was 0.354 (P-value < 0.001) and Z-score 21.6 in the 2016 Ethiopian Demographic and health survey (Figure 2). 
Incrementa Spatial 1 Autocorrelation Early marriage among reproductive-age women in Ethiopia.

To determine spatial clustering for early marriage, global spatial statistics were estimated using Moran's I value. As shown in the figure below a statistically significant z-scores indicate at $151.3 \mathrm{Km}$ distances where spatial processes promoting clustering are most pronounced. The incremental spatial Autocorrelation indicates that a total of 10 distance bands were detected with a beginning distance of 121813 meters. (Figure 3)

\section{Hot spot (Getis-Ord Gi) analysis:}

As shown in the figure below, the red color indicates the more intense clustering of high (hot spot) proportion early marriage preceding the survey period. A high proportion of early marriage was clustered at the Amhara, Afar, and Gambella region of Ethiopia. Whereas, Amhara, SNNPR and Addis Ababa regions of Ethiopia were less risk area. (Figure 4)

Spatial Sat Scan analysis of Early marriage among women across regions of Ethiopia, 2016

Most likely (primary clusters) and secondary clusters of early marriage were identified. A total of 163 significant clusters were identified. Of these, 87 of them were most likely (primary) clusters and 76 were secondary clusters. The primary clusters' spatial window was located in the Amhara Tigray and Benishangul regions, which was centered at 11.66 $\mathrm{N}, 37.31 \mathrm{E}$ with a $254.88 \mathrm{~km}$ radius, and Log-Likelihood ratio (LLR) of 126.18, at p < 0.001. It showed that women within the spatial window had 1.28 times higher risk of early marriage than women outside the window. The secondary clusters' spatial window was typically located in the Somali and Oromia regions. Which was centered at $6.30 \mathrm{~N}, 41.25 \mathrm{E}$ with $340.06 \mathrm{~km}$ radius, and LLR of 18.95 at p-value $<0.001$ It showed that women within the spatial window had a 1.11 times higher risk of early marriage than women outside the window (Figure 5 and Table 2). 
Table 2: SaT Scan analysis of Early marriage among women in the last five years in Ethiopia, 2016 


\begin{tabular}{|c|c|c|c|c|c|c|c|}
\hline$\overline{r \text { type }}$ & $\begin{array}{l}\text { Significant } \\
\text { Enumeration } \\
\text { Areas(clusters) } \\
\text { detected }\end{array}$ & $\begin{array}{l}\text { Coordinates } \\
\text { /Radis }\end{array}$ & Populations & Cases & $\mathbf{R R}$ & LLR & $\begin{array}{l}\mathrm{P} \text { - } \\
\text { value }\end{array}$ \\
\hline tary & 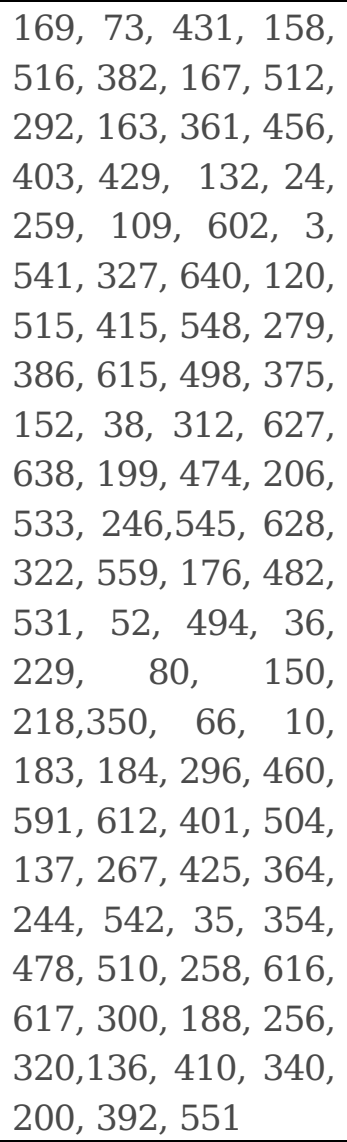 & $\begin{array}{l}(11.699828 \\
N, \\
37.313042 \\
\mathrm{E}) / 254.88 \\
\mathrm{~km}\end{array}$ & 2756 & 2803 & 1.28 & 126.18 & $\begin{array}{l}< \\
0.001\end{array}$ \\
\hline idary & $\begin{array}{l}\text { 480, 187, } 318, \\
286,289,556, \\
472,394,452, \\
278,377,123, \\
422,562,520, \\
34,213,319, \\
358,85,164, \\
518,208,26, \\
529,619,405, \\
245,468,576, \\
313,122,524, \\
476,365,372, \\
589,316,12, \\
391,438,95, \\
412,198,578, \\
445,600,492, \\
522,398,308, \\
506,171,634, \\
497,7,71,216, \\
232,521,215, \\
588,553,148, \\
32,149,138, \\
408,458,543,\end{array}$ & $\begin{array}{l}\text { (6.300866 } \\
\text { N, } \\
41.252617 \\
\mathrm{E}) / 340.06 \\
\mathrm{~km}\end{array}$ & 2691 & 1833 & 1.11 & 61.2918 .95 & $\begin{array}{l}< \\
0.001\end{array}$ \\
\hline
\end{tabular}




\section{Interpolation of Early Marriage in Ethiopia}

The predicted early marriage over the area increases from green to red-colored areas. The red color indicates high-risk areas of predicted early marriage and the green color indicates the predicted low-risk areas of early marriage. The Amhara, Afar, Gambela and some parts of the Somali region, were predicted high-risk areas of early marriage. Continuous images produced by interpolating (Kriging interpolation method) early marriage among women (Figure 6)

\section{Factors associated with early marriage.}

After adjusting for different confounding variables, Age group, women education level and region were significantly associated with early marriage in Ethiopia. As age group increases the odds of early marriage decreases.Women's in age group of 20-34 and 35-49 were decrease by $61 \%$ (AOR $=0.39 ; 95 \% \mathrm{CI}$ : $0.30,0.51$ ) as compared to age group of women 15 to 19. The odds of early marriage decreases as educational level increases. Being primary education level of women decreases the odds early marriage by $40 \%$ (AOR $=0.60$; 95\%CI: $0.51,0.71$, being secondary education level decreases the odds of early marriage by $81 \%(\mathrm{AOR}=0.19 ; 95 \% \mathrm{CI}: 0.13,0.26]$, being higher education level decreases the odds early marriage by $89 \%(\mathrm{AOR}=0.11 ; 95 \% \mathrm{CI}: 0.07,0.18]$ as compared to women unable to read and write.The odds of early marriage increase by $47 \%$ (AOR=1.47; 95\%CI: 1.16, 1.87) in Amhara and 42\% (AOR= 1.47; 95\%CI: 1.16, 1.87) Gambella Region as compared to women live in Tigray region. The odds of early marriage decreases by $21 \%$ (AOR=0.79; 95\%CI: $0.63,0.99)$ in Oromia, 45\% (AOR=0.55; 95\%CI: 0.42, 0.70) in Somali, $28 \%$ $(\mathrm{AOR}=0.72 ; 95 \% \mathrm{CI}: 0.56,0.92)$ in SNNP and Harari, 65\% (AOR=0.35; 95\%CI: 0.25, 0.47) and $31 \%(\mathrm{AOR}=0.69 ; 95 \% \mathrm{CI}: 0.52,0.91)$ as compared to women live in Tigray region (Table 3). 
Table 3: Multiple logistic regression analysis of factors associated with early marriage among reproductive age in Ethiopia, EDHS 2016 


\begin{tabular}{|c|c|c|c|}
\hline Variables & \begin{tabular}{l}
\multicolumn{1}{c}{ Marriage } \\
year \\
$<18$ year $>=18$ \\
year
\end{tabular} & $\begin{array}{l}\text { Crude odds ratio } \\
\text { (95\% CI) }\end{array}$ & $\begin{array}{l}\text { Adjusted odds ratio } \\
(95 \% \mathrm{CI})\end{array}$ \\
\hline \multicolumn{4}{|l|}{ Place of Residence } \\
\hline Urban & 1077 & 1 & 1 \\
\hline Rural & \begin{tabular}{|l}
6297 \\
3247
\end{tabular} & $2.03(1.71,2.42)$ & $0.95(0.72,1.18)$ \\
\hline \multicolumn{4}{|l|}{ Age group } \\
\hline$<20$ & \begin{tabular}{|l|}
966 \\
271
\end{tabular} & 1 & 1 \\
\hline $20-34$ & \begin{tabular}{|l|}
3692 \\
2576
\end{tabular} & $0.41(0.32,0.50)$ & $0.39(0.30,0.51)^{*}$ \\
\hline $35-49$ & \begin{tabular}{|l|}
2664 \\
4477
\end{tabular} & $0.50(0.40,0.63)$ & $0.39(0.30,0.51)^{*}$ \\
\hline \multicolumn{4}{|l|}{$\begin{array}{l}\text { Women Level of } \\
\text { education }\end{array}$} \\
\hline $\begin{array}{l}\text { Unable to read and } \\
\text { write }\end{array}$ & 4909 & 1 & 1 \\
\hline Primary education & 2039 & $0.68(0.59,0.78)$ & $0.60(0.51,0.71) *$ \\
\hline Secondary education & 267 & $0.23(0.18,0.30)$ & $0.19(0.13,0.26)^{*}$ \\
\hline Higher education & 106 & $0.12(0.08,0.17)$ & $0.11(0.07,0.18)^{*}$ \\
\hline \multicolumn{4}{|l|}{$\begin{array}{l}\text { Husband Level of } \\
\text { education }\end{array}$} \\
\hline $\begin{array}{l}\text { Unable to read and } \\
\text { write }\end{array}$ & $\begin{array}{l}3247 \\
1516\end{array}$ & 1 & 1 \\
\hline Primary education & $\begin{array}{c}3448 \\
1323\end{array}$ & $0.86(0.74,1.03)$ & $1.10(0.93,1.30)$ \\
\hline Secondary education & 466 & $0.42(0.34,0.53)$ & $0.89(0.70,1.14)$ \\
\hline Higher education & 241 & $0.23(0.17,0.31)$ & $0.82(0.55,1.23)$ \\
\hline \multicolumn{4}{|l|}{ Wealth quartile } \\
\hline Poor & 1559 & 1 & 1 \\
\hline Middle & $\begin{array}{l}1530 \\
793\end{array}$ & $0.92(0.78,1.08)$ & $0.95(0.79,1.14)$ \\
\hline Rich & \begin{tabular}{|l|}
2747 \\
2070 \\
\end{tabular} & $0.63(0.53,0.75)$ & $0.98(0.80,1.21)$ \\
\hline \multicolumn{4}{|l|}{ Region } \\
\hline Tigray & 542 & 1 & 1 \\
\hline Afar & 81 & $1.67(1.25,2.23$ & $1.25(0.92,1.70)$ \\
\hline Amhara & 2108 & $1.51(1.19,1.93)$ & $1.47(1.16,1.87)^{*}$ \\
\hline Oromia & 2751 & $0.91(0.72,1.75)$ & $0.79(0.63,0.99) *$ \\
\hline Somalia & 199 & $0.70(0.55,0.89)$ & $0.55(0.42,0.70) *$ \\
\hline Benishangul Gumuz & 81 & $1.04(0.80,1.35)$ & $0.94(0.70,1.25)$ \\
\hline SNNP & 343 & $0.77(0.60,0.99)$ & $0.72(0.56,0.92)^{*}$ \\
\hline Gambela & 21 & $0.97(0.75,1.27)$ & $1.42(1.02,1.97)^{*}$ \\
\hline Harari & 15 & $0.65(0.50,0.85)$ & $0.72(0.55,0.95)^{*}$ \\
\hline Addis Ababa & 141 & $0.25(0.20,0.31)$ & $0.35(0.25,0.47)^{*}$ \\
\hline
\end{tabular}




\begin{tabular}{|l|ll|l|l|} 
Dire Dawa & 34 & 27 & $0.69(0.53,0.90)$ & $0.69(0.52,0.91)^{*}$ \\
\hline Media exposure & & & 1 \\
\hline No media exposure & 5968 & 3095 & 1 & $1.17(0.97,1.42)$ \\
\hline Has media exposure & 1353 & 1229 & $0.59(0.49,0.66)$ & \\
\hline $\begin{array}{l}\text { Occupation status of } \\
\text { mothers }\end{array}$ & & & 1 \\
\hline No & 3551 & 2127 & 1 & $1.08(0.96,1.23)$ \\
\hline Yes & 3771 & & $1.02(0.95,1.15)$ & \\
\hline
\end{tabular}

* indicates significance at 5\% level and CI: Confidence Interval

\section{Discussion}

This study has strengths of having large dataset include thee EDHS survey and were nationally representative. Multiple logistic regression analysis was used to reduce confounding among explanatory variables. The spatial analysis was also used for identifying hotspot areas, most likely clusters and the prediction was performed to predict unsampled/unmeasured areas in the country.

Despite Ethiopia has instituted laws inhibiting marriage under 18 years and early female marriage is associated with a number of poor social and physical outcomes for young women and their offspring(19) child marriage is a norm in the country. Similarly, more than $62 \%$ of the study participants in this study were married before they reached the age of 18 years. This finding is higher than the findings from Zambia, 31.4\% (20), and Ghana, 29.9\% (21). This might be explained by the disparity in educational, socioeconomic and cultural differences between the study settings. The problem needs a comprehensive approach, including their families, the community, the government, and religious leaders, to reduce child marriage, teenage childbearing, and its negative consequences.

The spatial distribution of early marriage in Ethiopia was non-random. The spatial distribution of early marriage was high in Amhara, Afar, Gambella regional states of Ethiopia. The 2016 EDHS most likely significant cluster located at Amhara and Tigray and Secondary clusters were located in Somali and Oromia regional states of Ethiopia. The possible geographical variation of Early marriage Ethiopia might be socio-demographic factors, cultural behaviors.

Early marriage is often common among poor and less educated communities. A similar finding is found in this study. Women who attended primary education and above were less likely to marry before 18 years compared to their counterparts. Because educated women have a chance to determine their first age of marriage and are more likely to have a say in decision-making regarding the size of their families and the spacing of their children. In addition, educated women are also likely to be more informed and knowledgeable about contraception and the healthcare needs of their children $(22,23)$.

In this study, women were more likely to early marriage in other regions of the country compared to Adds Ababa. It is true that poverty is one of the most powerful drivers of the harmful practices and poor 
families believed they will be more financially secure once their daughters are married off and out of their responsibility. In addition, poor families want to reduce the number of children to feed, clothe and educate and families may agree to child marriage because of community pressures and norms (23).

\section{Strength and limitation of the study}

This study has strengths of having large dataset include thee EDHS survey and were nationally representative. Multiple logistic regression analysis was used to reduce confounding among explanatory variables. The spatial analysis was also used for identifying hotspot areas, most likely clusters and the prediction was performed to predict unsampled/unmeasured areas in the country. However, the limitation of this study is the cross-sectional nature of the study design may affect causality.

\section{Conclusion}

Early marriage was high in Ethiopia. High-risk area of early marriage was located in Amhara, Afar, and Gambella and special attention should be given for identified risk areas. Therefore, providing educational opportunities to young girls was important in addition to inhibiting the marriage of girls under 18 years.

\section{Abbreviations}

$\mathrm{Cl}=$ Confidence Interval EDHS = Ethiopia Demographic and Health Survey; SNNPR = Southern Nation Nationality Perole of Ethiopia Region

\section{Declarations}

\section{Acknowledgment}

I would like to than the EDHS measure for accessing the data

\section{Author contribution}

Conceptualization: Zemenu Tadesse Tessema

Data curation: Zemenu Tadesse Tessema

Formal analysis: Zemenu Tadesse Tessema

Methodology: Zemenu Tadesse Tessema

Writing-original draft: Zemenu Tadesse Tessema

Writing-review \&editing: Zemenu Tadesse Tessema

\section{Funding}


I didn't receive any funds for this study.

\section{Availability of data and materials}

The datasets generated during the study are publicly available from the Measure DHS Website www.measuredhs.com

\section{Ethical approval and consent to participate}

I, author, submitted a proposal to DHS Program/ICF International Inc, and permission was confirmed from the International Review Board of Demographic and Health Surveys (DHS) program data archivists to download the dataset for this study

\section{Consent for publication}

Not applicable.

\section{Competing interests}

The author declare that no competing interests.

\section{Author details}

Department of Epidemiology and Biostatics, Institute of Public Health College of Medicine and Health Science, University of Gondar, Gondar, Ethiopia.

\section{References}

1. WHO. Child marriages: 39000 every day. WHO Media Cent [Internet]. 2013;(March 2013):1-7. Available from:

https://www.who.int/mediacentre/news/releases/2013/child_marriage_20130307/en/\#content

2. UNICEF. 25 million child marriages prevented in last decade due to accelerated progress, according to new UNICEF estimates. New York; Accessed from https://www.unicef.org/eca/press-releases/25million-child-marriages-prevented on August 19, 2019; 2018.

3. United Nations Children's Fund. Early marriage: a harmful traditional practice. New York; 2005.

4. Population Council and Government of the Republic of Zambia, U. “Child Marriage in Zambia... Lusaka, Zambia; 2017.

5. Central Statistical Agency [Ethiopia] and ICF International. Ethiopia Demographic and Health Survey 2016. Addis Ababa, Ethiopia, and Rockville, Maryland, USA: CSA and ICF.; 2016.

6. UNFPA Engender Health. Obstetric Fistula Needs Assessment Report: Findings from Nine African Countries. 2003.

7. Nour NM. Health consequences of child marriage in Africa. Emerg Infect Dis. 2006;12(11):1644. 
8. odon Q, C. Male, A. Nayihouba, A. Onagoruwa, A. Savadogo, A. Yedan, et al. Economic Impacts of Child Marriage: Global Synthesis Report, Washington, DC: The World Bank and International Center for Research on Women. 2017;

9. Erulkar A. Early marriage, marital relations and intimate partner violence in Ethiopia. Int Perspect Sex Reprod Heal. 2013/04/16. 2013;39(1):6-13.

10. Wondie $Y$, Zemene W, Reschke K, Schroder H. Early marriage, rape, child prostitution, and related factors determining the psychosocial effects severity of child sexual abuse in Ethiopia. J Child Sex Abus. 2011/06/11. 2011;20(3):305-21.

11. Bezie M, Addisu D. Determinants of early marriage among married women in Injibara town, north West Ethiopia: community-based cross-sectional study. BMC Womens Heal. 2019/11/11. 2019;19(1):134.

12. Erulkar A, Tamrat T. Evaluation of a reproductive health program to support married adolescent girls in rural Ethiopia. Afr J Reprod Heal. 2014/07/16. 2014;18(2):68-76.

13. Gage AJ. Child marriage prevention in Amhara Region, Ethiopia: association of communication exposure and social influence with parents/guardians' knowledge and attitudes. Soc Sci Med. 2013/10/29. 2013;97:124-33.

14. Alemu Z. Early marriage - the silent carnage of our women. Newsl Inter Afr Comm Tradit Pr Affect Heal Women Child. 1988/03/01. 1988;(5):5-6.

15. Berhane A, Biadgilign S, Berhane A, Memiah P. Male involvement in family planning program in Northern Ethiopia: an application of the Transtheoretical model. Patient Educ Couns. 2015/01/30. 2015;98(4):469-75.

16. Ketema H, Erulkar A. Married Adolescents and Family Planning in Rural Ethiopia: Understanding Barriers and Opportunities. Afr J Reprod Heal. 2019/01/12. 2018;22(4):26-34.

17. O'Sullivan D. Geographically Weighted Regression: The Analysis of Spatially Varying Relationships (review). Geogr Anal. 2003;35(3):272-5.

18. Kulldorff M. Theory and Methods A spatial scan statistic. Commun Stat. 1997;26(6)(February 2013):1481-96.

19. Field E, Ambrus A. Early marriage, age of menarche, and female schooling attainment in Bangladesh. J Polit Econ. 2008;116(5):881-930.

20. Chitempa N. Girl Empowerment and Child Marriage: Empowering girls to prevent and end child marriage in Zambia. 2018;

21. de Groot R, Kuunyem MY, Palermo T. Child marriage and associated outcomes in northern Ghana: a cross-sectional study. BMC Public Health. 2018;18(1):285.

22. Wodon Q, Male C, Nayihouba A, Onagoruwa A, Savadogo A, Yedan A, et al. Economic impacts of child marriage: global synthesis report. 2017;

23. Ahmed T. Child marriage: A discussion paper. Bangladesh J Bioeth. 2015;6(2):8-14. 


\section{Table}

Table 1: socio-demographic and economic characteristics of the study participants, EDHS 2016. 


\begin{tabular}{|c|c|c|}
\hline Variables & $\begin{array}{l}\text { Frequency } \\
\mathrm{n}=11,646\end{array}$ & Percentages \\
\hline \multicolumn{3}{|l|}{ Age at marriage } \\
\hline Less than 18 year & 4324 & 37.13 \\
\hline 18 years and above & 7322 & 62.87 \\
\hline \multicolumn{3}{|l|}{ Mother's age } \\
\hline$<20$ & 1237 & 10.61 \\
\hline $20-34$ & 6268 & 53.81 \\
\hline $35-49$ & 4142 & 36.56 \\
\hline \multicolumn{3}{|l|}{ Religion } \\
\hline Orthodox & 4970 & 42.67 \\
\hline Muslim & 3906 & 33.54 \\
\hline Protestant & 2498 & 21.45 \\
\hline Others* & 271 & 2.33 \\
\hline \multicolumn{3}{|l|}{ Residence } \\
\hline Urban & 2102 & 18.05 \\
\hline Rural & 9544 & 81.95 \\
\hline \multicolumn{3}{|l|}{ Region } \\
\hline Tigray & 487 & 7.23 \\
\hline Afar & 108 & 0.93 \\
\hline Amhara & 2888 & 24.79 \\
\hline Oromia & 4433 & 38.08 \\
\hline Somalia & 358 & 3.07 \\
\hline Benishangul Gumuz & 125 & 1.07 \\
\hline SNNP & 12310 & 19.08 \\
\hline Gambela & 34 & 0.79 \\
\hline Harari & 29 & 0.25 \\
\hline Addis Ababa & 451 & 3.88 \\
\hline Dire Dawa & 63 & 0.54 \\
\hline \multicolumn{3}{|l|}{ Mother's Educational status } \\
\hline Unable to read and write & 7059 & 60.61 \\
\hline Primary education & 3351 & 28.77 \\
\hline Secondary education & 764 & 6.56 \\
\hline Higher education & 473 & 4.06 \\
\hline \multicolumn{3}{|c|}{ Husband Educational status } \\
\hline Unable to read and write & 4763 & 46.59 \\
\hline Primary education & 3772 & 39.90 \\
\hline Secondary education & 975 & 9.54 \\
\hline Higher education & 713 & 6.97 \\
\hline \multicolumn{3}{|l|}{ Mother's Occupation } \\
\hline Not working & 5968 & 48.76 \\
\hline Working & 5679 & 51.24 \\
\hline \multicolumn{3}{|l|}{ husband Occupation } \\
\hline Not working & 807 & 5.16 \\
\hline Working & 9416 & 94.84 \\
\hline \multicolumn{3}{|l|}{ Media exposure } \\
\hline No media exposure & 2583 & 22.10 \\
\hline
\end{tabular}




\begin{tabular}{|l|l|l|} 
Has media exposure & 7782 & 77.90 \\
\hline Wealth index & & \\
\hline Poor & 4504 & 38.67 \\
\hline Middle & 2324 & 19.95 \\
\hline Rich & 4819 & 41.38 \\
\hline
\end{tabular}

* Others represent Catholic and Traditional religion follower

\section{Figures}

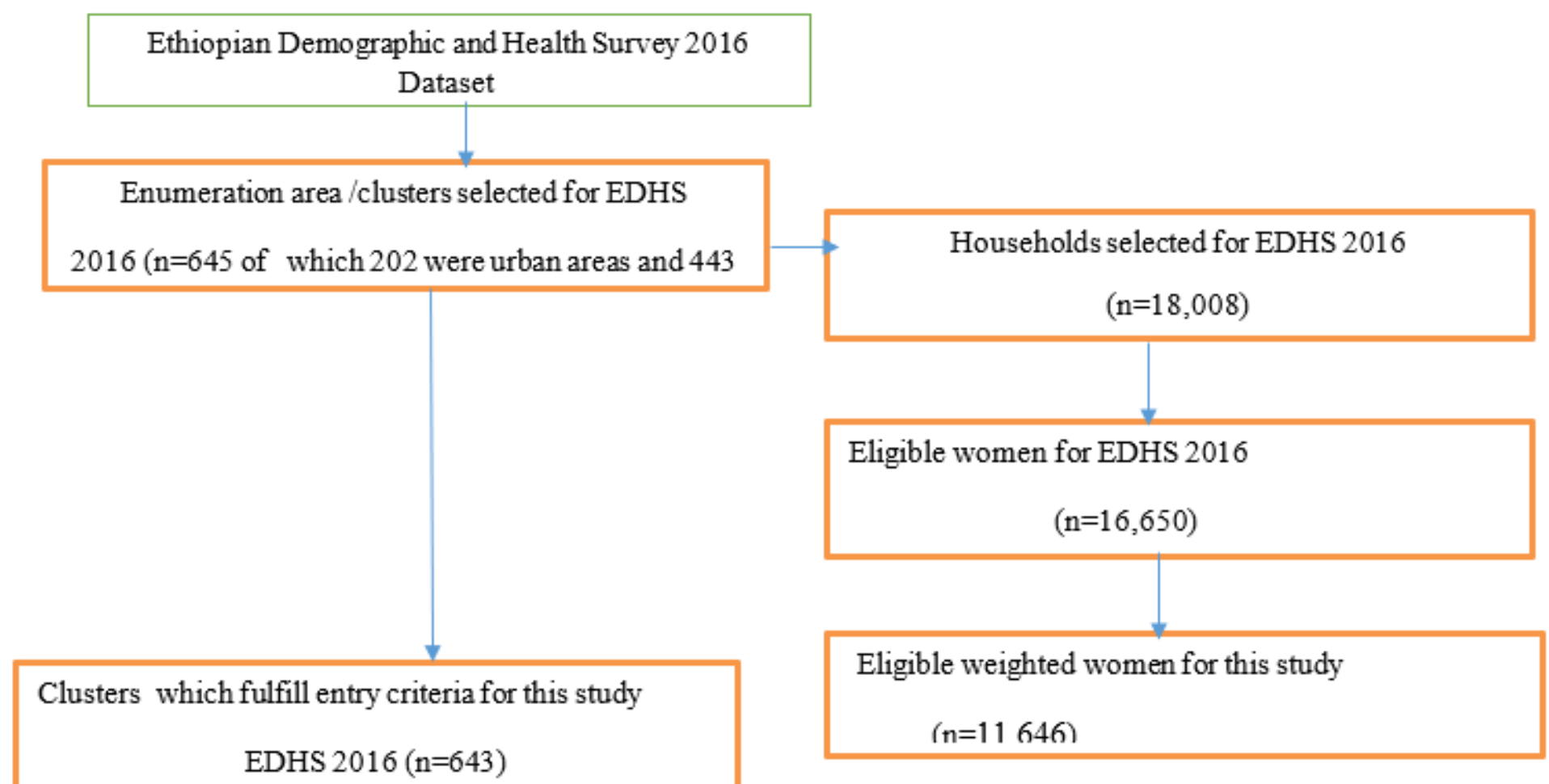

\section{Figure 1}

Sampling procedures of age at first marriage among Ethiopia women age 15-49 using EDHS 2016 data. 


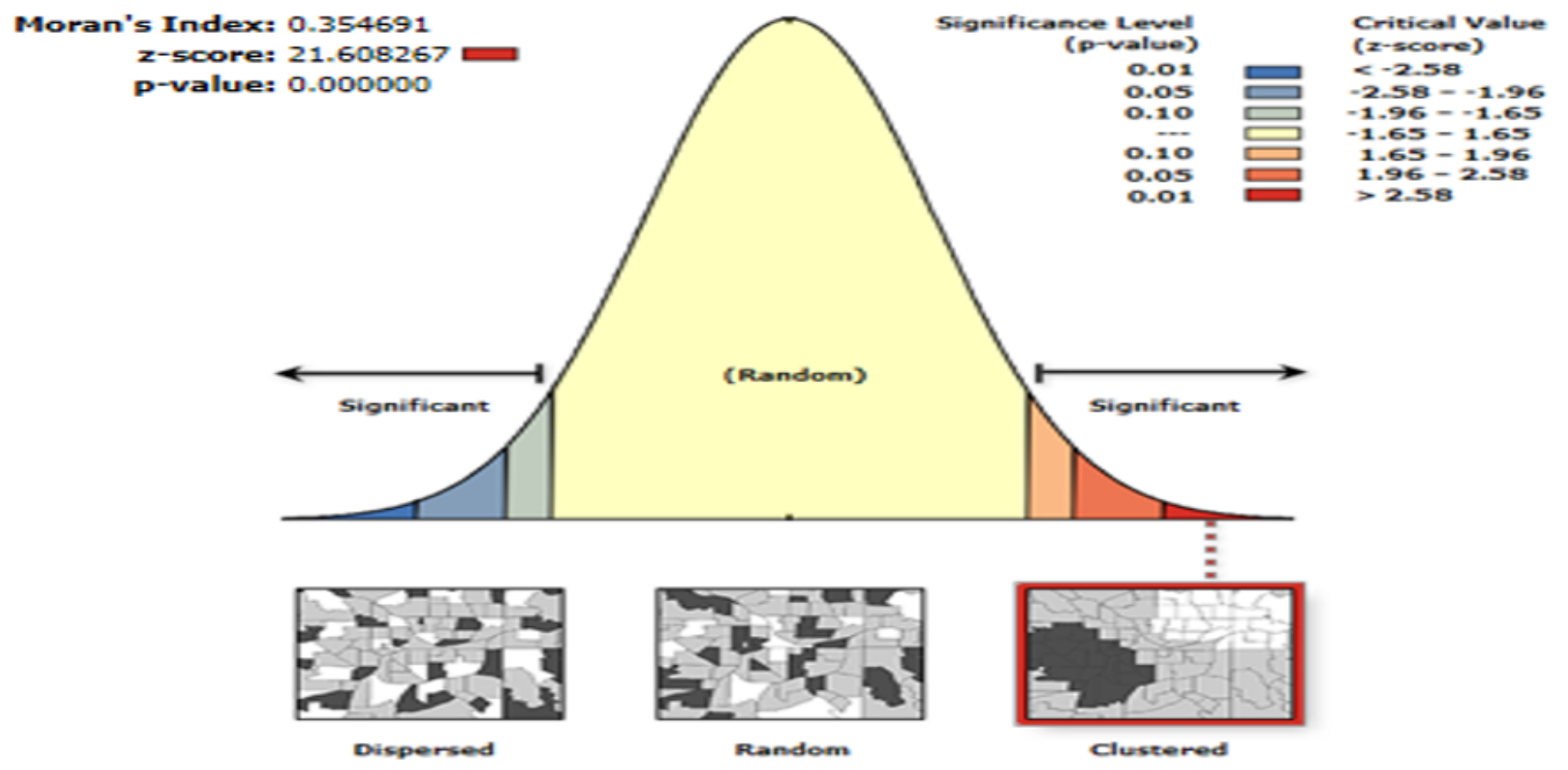

Given the $z$-score of 21.6082673801 , there is a less than $1 \%$ likelihood that this clustered pattern could be the result of random chance.

\section{Figure 2}

Spatial autocorrelation of Early marriage in Ethiopia among the reproductive age group in EDHS 2016.

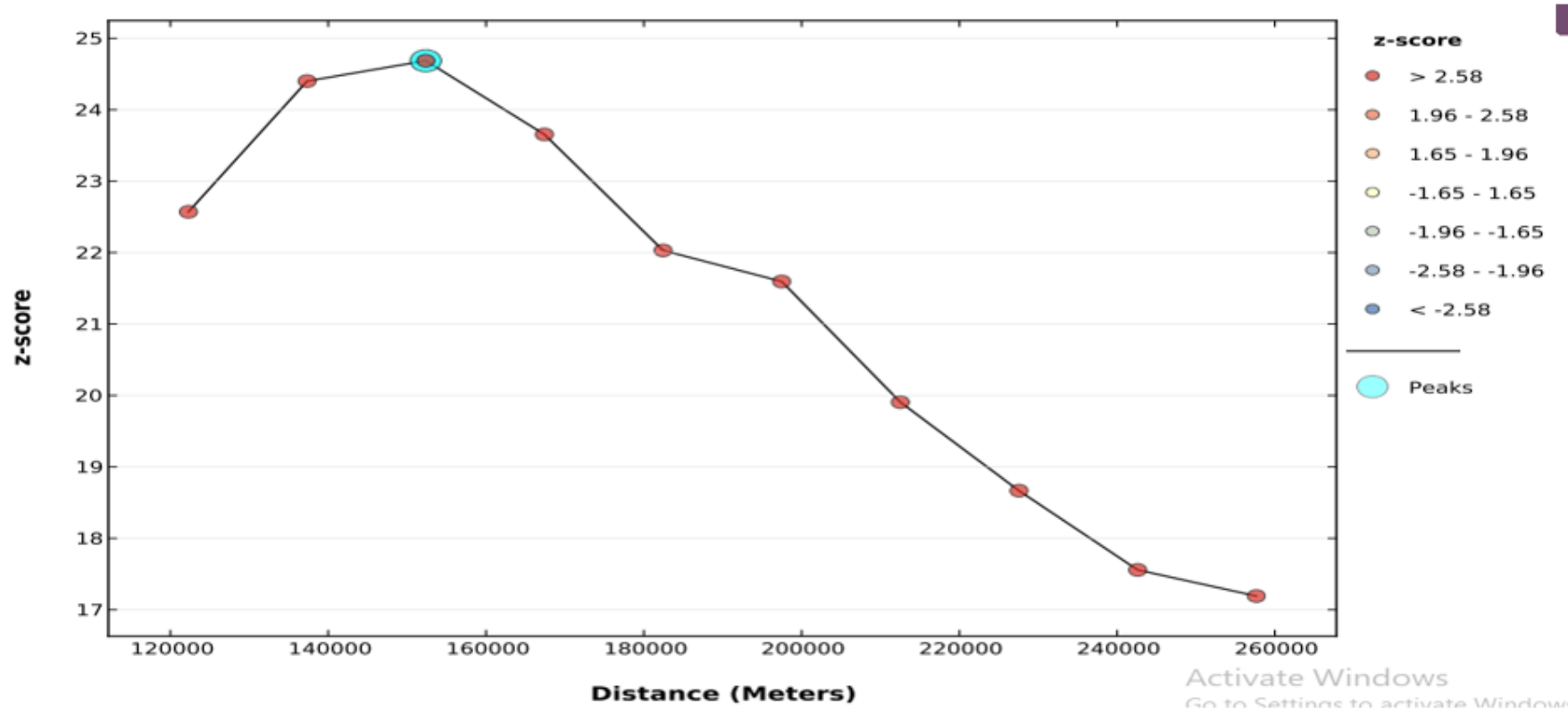

\section{Figure 3}

The spatial autocorrelation of early marriage among reproductive age group women in Ethiopia by a function of distance. 


\section{Hot Spot Analysis}

- Cold Spot - $99 \%$ Confidence $\tilde{\Lambda}$
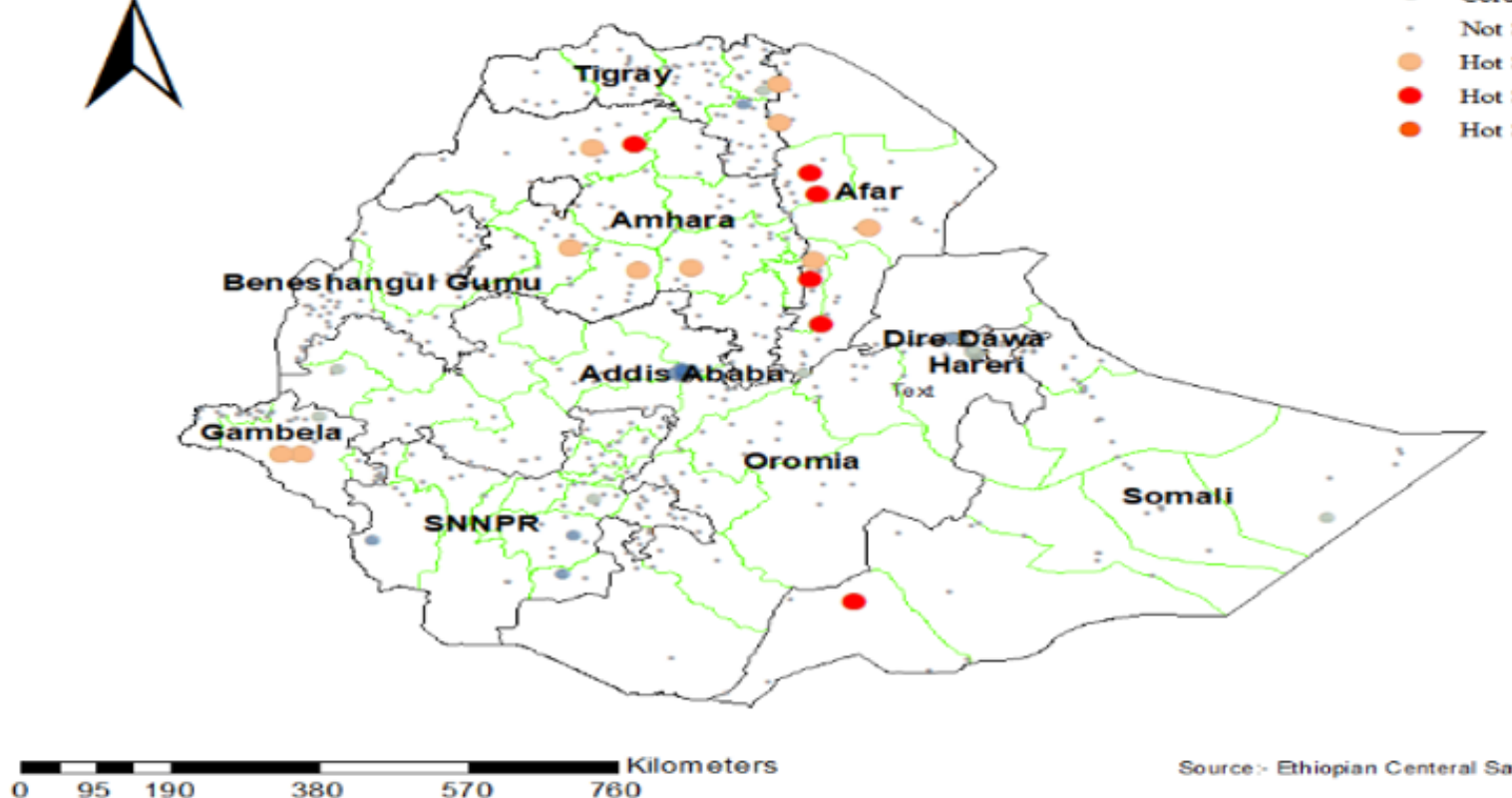

Source:- Ethiopian Centeral Satatistica Agency shape file 2013

\section{Figure 4}

Hot spot analysis of Early marriage among women within 5 years preceding the survey in Ethiopia, 2016 


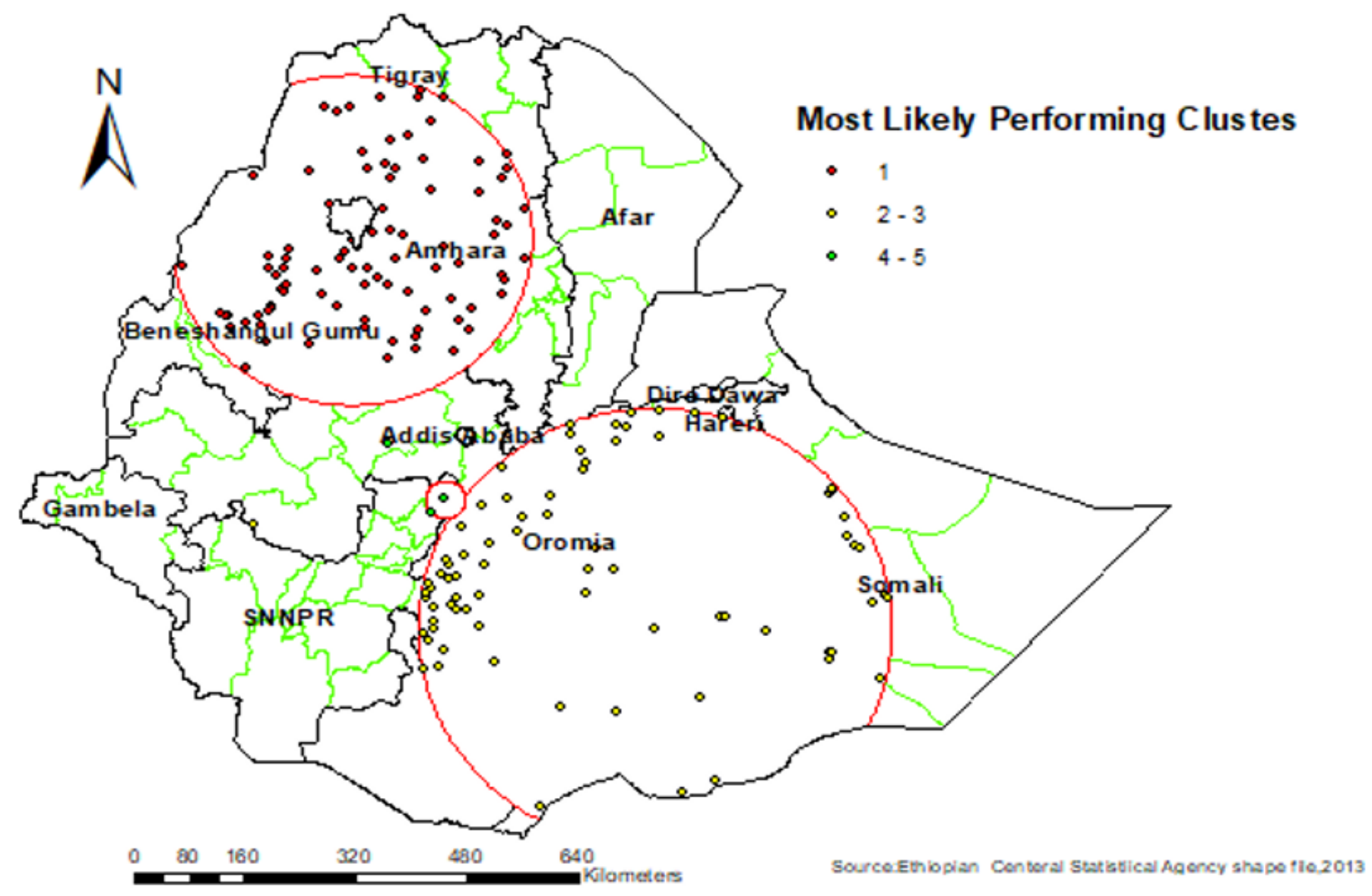

Figure 5

SatTscan analysis result of Early marriage among Reproductive age women in Ethiopia EDHS 2016 

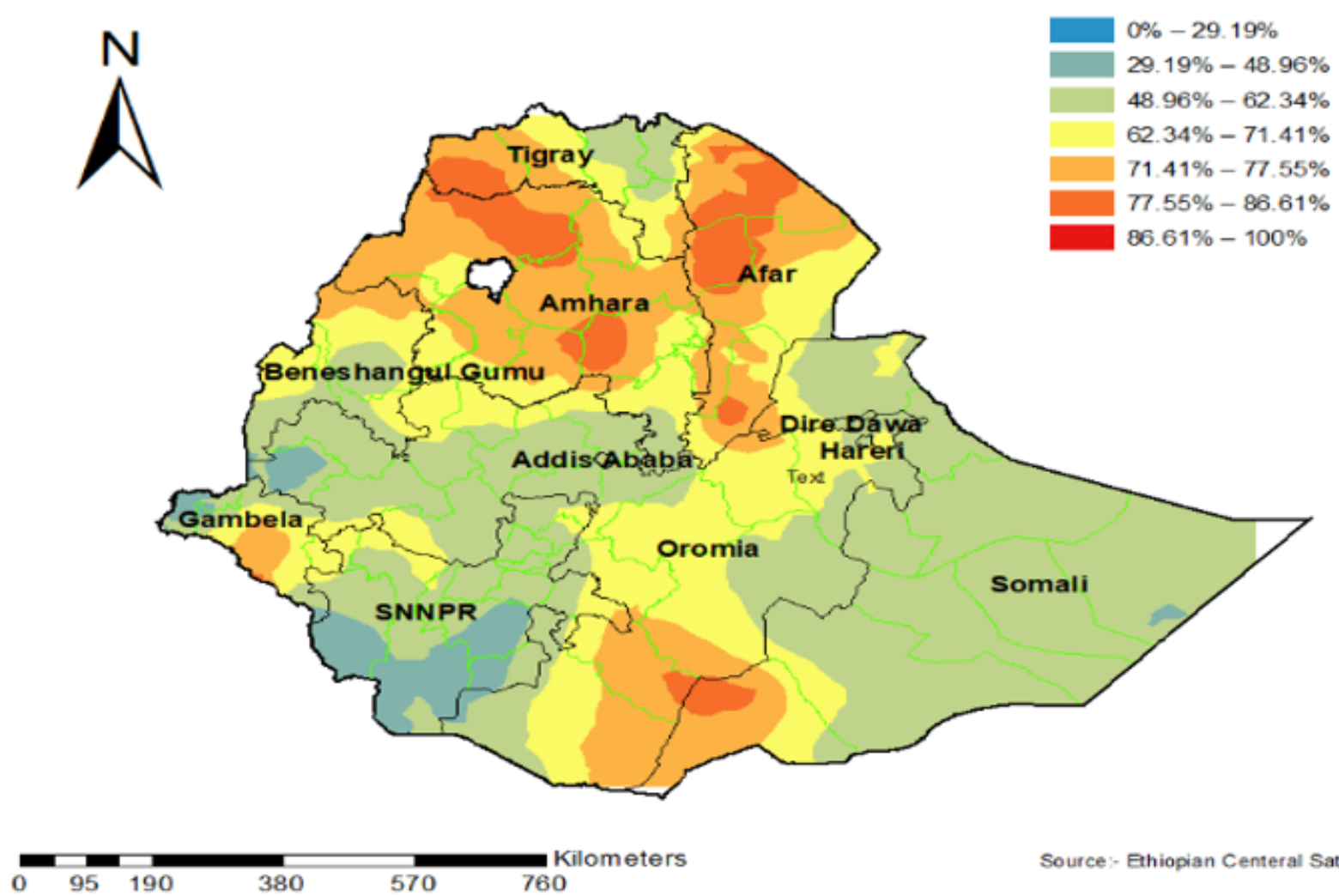

Source:- Ehiopian Centeral Satatistica Agency shape file 2013

Figure 6

Interpolation of high-risk fertility behavior among reproductive-age women in Ethiopia, 2016 